\title{
Por Mais Mulheres na Computação: análise dos trabalhos publicados no X Women in Information Technology
}

\author{
Gisela Cesario', Noélya Gonçalves da Silveira ${ }^{1}$, \\ Sílvia Amélia Bim¹, Cristiano Maciel $^{2}$
}

${ }^{1}$ Departamento Acadêmico de Informática (DAINF) - Universidade Tecnológica Federal do Paraná (UTFPR) Av. Sete de Setembro, 3165, Rebouças - Curitiba - PR - 80230-901 Brasil

${ }^{2}$ Instituto de Computação - Universidade Federal de Mato Grosso (UFMT) Av. Fernando Corrêa da Costa, 2367, Boa Esperança - Cuiabá- MT - Brasil

giselaa@alunos.utfpr.edu.br, lyacampozano@gmail.com, sabimeutfpr.edu.br, cmaciel@ufmt.br

\begin{abstract}
This article aims to present an analysis of the works published in the $10^{\text {th }}$ Women in Information Technology (WIT), event promoted by the Brazilian Society of Computing. The results show that there are actions to encourage greater participation of women in the areas of Computing in almost all Brazilian regions. In general, the publications of the $10^{\text {th }}$ WIT portray actions developed by higher education institutions.
\end{abstract}

Resumo. O presente artigo tem por objetivo apresentar uma análise dos trabalhos publicados no X Women in Information Technology (WIT), evento promovido pela Sociedade Brasileira de Computação. Os resultados indicam que já existem projetos em todas as regiões do Brasil para fomentar a maior participação das mulheres nas áreas de Computação, em geral, desenvolvidos por instituições públicas de ensino superior.

\section{Introdução}

A representatividade das mulheres, estudantes, nos cursos da área de Computação vem decrescendo desde 2001 [Oliveira et al., 2014]. De acordo com o último relatório ${ }^{1}$ divulgado pela Sociedade Brasileira de Computação (SBC), observa-se que em 2015 nos cursos de Computação 14,65\% das(os) matriculados(as) são mulheres e, dessas, 16\% concluem o curso.

Como tentativa de aumentar a proporção de mulheres na área de Tecnologia de Informação (TI), existe uma preocupação em diversas universidades, instituições de fomento e empresas em criar ações de incentivo que promovam o aumento da representatividade das mulheres na Computação.

Em 2011, a Sociedade Brasileira de Computação (SBC) começou a apoiar sua regional no Mato Grosso a desenvolver o Programa Meninas Digitais, sendo oficialmente institucionalizado por essa sociedade em 2016. Tal iniciativa visa "divulgar a área de Computação para despertar o interesse de estudantes do ensino

1 http://sbc.org.br/documentos-da-sbc/summary/133-estatisticas/1074-educacao-superior-emcomputacao-estatisticas-2015 
fundamental/médio/tecnológico" [Maciel e Bim, 2016], incentivando e apoiando a criação de projetos que divulguem a área. Este Programa também realiza o Fórum Meninas Digitais, incluso na programação do WIT - Women in Information Technology, evento base do CSBC - Congresso da SBC. Desde 2007, este workshop acontece anualmente para discutir estratégias que visam o aumento da participação de mulheres em TI no Brasil. Em julho de 2016, foi realizada a $10^{\text {a }}$ edição do WIT. Pela primeira vez foi feita a submissão de trabalhos apresentados na forma de pôsteres.

Assim, o objetivo deste artigo é apresentar a análise dos trabalhos publicados no X WIT, mapeando as ações realizadas no Brasil com identificação das instituições responsáveis, estados e a natureza das ações. Para isso, este artigo apresenta, na seção 2, a metodologia utilizada na pesquisa. A seção 3 discute sobre os resultados obtidos. Por fim, a seção 4 é composta pelas considerações finais seguida das referências bibliográficas.

\section{Método de Pesquisa}

Para realizar a análise dos artigos publicados nos anais do X WIT, realizou-se uma revisão sistemática com as seguintes etapas: (1) definição das questões de pesquisa; (2) leitura dos artigos; (3) extração dos dados; e (4) análise dos resultados obtidos.

A questão principal da pesquisa era: Quais projetos para aumentar a representatividade das mulheres na área da Computação no Brasil são relatados nos trabalhos publicados no $\boldsymbol{X}$ WIT? Em seguida, três perguntas foram derivadas desta questão. São elas: QP1 - Em quais estados esses projetos foram criados? QP2 - Quem são as instituições responsáveis por esses projetos? QP3 - Quais ações foram realizadas por estes projetos?

Com intuito de responder às Questões de Pesquisa, foi realizada a leitura dos vinte e cinco artigos publicados nos anais do $\mathrm{X} \mathrm{WIT}^{2}$. Nesta etapa, todos os trabalhos foram primeiramente analisados para verificar se tratavam de relatos sobre projetos no contexto brasileiro. Desta forma, um artigo foi descartado para a próxima etapa pois apresentava um levantamento de ações estrangeiras. Embora relevantes, outros seis artigos foram descartados pois relatavam pesquisas realizadas sobre o tema Mulheres na Computação. E por fim, mais dois artigos foram descartados, um deles por ser um relato de experiência vivencial e o outro por ser uma proposta de jogo.

Na etapa de extração de dados, os dezesseis artigos selecionados na etapa anterior, foram novamente lidos em busca de respostas para as Questões de Pesquisa. A seção a seguir apresenta a última etapa da pesquisa: a análise dos resultados.

\section{Resultados}

Neste tópico serão apresentados os resultados, categorizados por Questão de Pesquisa.

\section{QP1 - Em quais estados esses projetos foram criados?}

A Figura 1 ilustra a quantidade de projetos descritos nos artigos por estado brasileiro. É possível observar que há ações em todas as regiões do Brasil.

É necessário ressaltar que o fato do evento (X WIT) ter sido realizado em Porto Alegre pode ter influenciado na quantidade de projetos do estado do Rio Grande do Sul. Isto reforça a importância do caráter itinerante do evento, que a cada ano, juntamente com

2 http://ebooks.pucrs.br/edipucrs/anais/csbc/\#/evento/10wit 
o CSBC, é realizado em uma região diferente do Brasil.

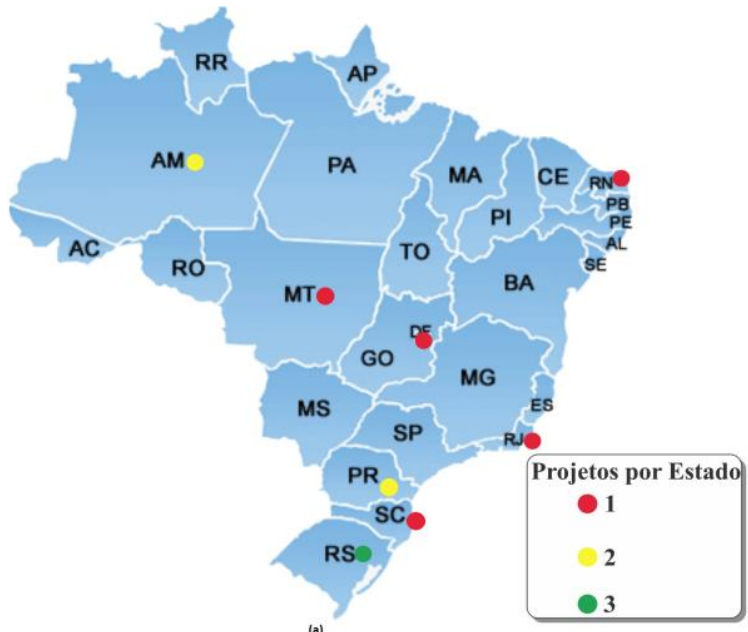

(a)

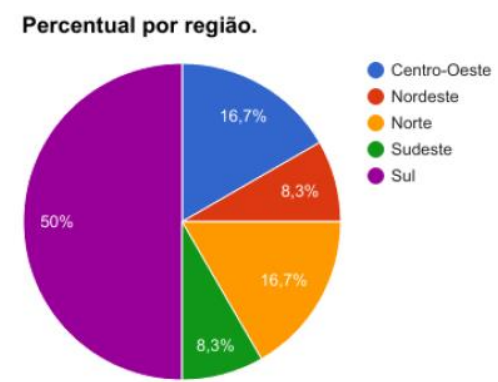

(b)

Figura 1. (a ) Projetos realizados por estados brasileiros. (b) Percentual por região

\section{QP2 - Quem são as instituições responsáveis por esses projetos?}

De acordo com a pesquisa verificou-se que todas as instituições responsáveis pelos projetos, com exceção da Universidade de Caxias do Sul, são universidades da rede pública do Brasil, conforme pode ser visto no gráfico da Figura 2:

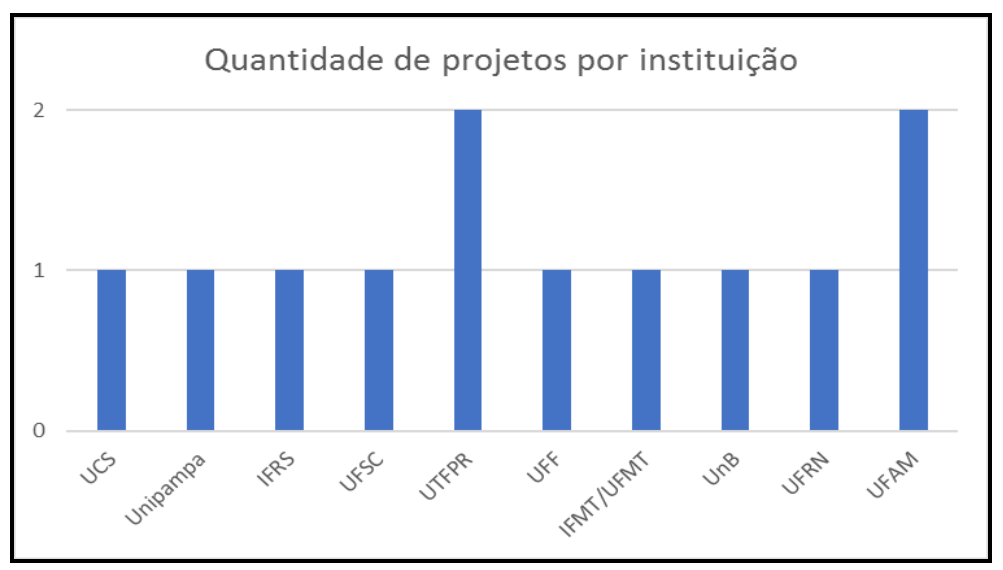

Figura 2. Universidades idealizadoras de projetos

Ao todo, foram mencionados doze projetos descritos no conjunto de artigos selecionados/analisados, a saber: (1) Trazendo Meninas para a Computação (UCS); (2) Gurias na Computação (Unipampa); (3) Mulheres e Jovens na Computação (IFRS Bento Gonçalves); (4) Meninas Digitais UFSC (UFSC - Araranguá); (5) Meninas, Computação e Música (UTFPR - Cornélio Procópio); (6) Emíli@s - Armação em Bits (UTFPR - Curitiba); (7) \#include <meninas.uff $>$ (UFF); (8) Meninas Digitais - Regional Mato Grosso (IFMT e UFMT); (9) Meninas.comp (UnB); (10) Projeto $^{3}$ (UFRN); (11)

\footnotetext{
${ }^{3}$ Nome do projeto não é citado no artigo. Entretanto, o artigo relata ações referentes "ao projeto".
} 
SciTech Girls’ Project (UFAM); (12) Cunhantã Digital (UFAM).

Destes, quatro não estavam relacionados no site do Programa Meninas Digitais ${ }^{4}$, a saber: Trazendo Meninas para a Computação (UCS), Mulheres e Jovens na Computação (IFRS - Bento Gonçalves), Meninas, Computação e Música (UTFPR - Cornélio Procópio) e SciTech Girls’ Project (UFAM).

Sobre os nomes dos projetos diretamente vinculados ao Programa Meninas Digitais é possível perceber uma diversidade de estratégias. Alguns se identificam explicitamente com o nome do Programa, criando especificações por regiões, estados ou instituições. Outros fazem uso de termos regionais e culturais, fortalecendo o vínculo com o contexto onde atuam. Embora com nomes diversificados os projetos fortalecem a relação com o Programa Meninas Digitais ao compartilharem suas experiências na primeira chamada de trabalhos que o programa cria dentro do contexto do WIT.

\section{QP3 - Quais ações foram realizadas por esses projetos?}

Diversas ações foram realizadas pelos projetos descritos nos artigos selecionados nesta pesquisa: palestras (citadas em 6 artigos), fórum (1), workshops (2), cursos EAD (1) e oficinas (13).

As oficinas realizadas abordam temas diversos na área de Computação: Interação Humano-Computador, Banco de Dados, Eletrônica, Programação, Robótica e Raciocínio Lógico. As oficinas de Programação são as mais citadas nos artigos analisados, seis citações no total, seguidas de duas citações sobre oficinas de Eletrônica e duas oficinas de Robótica. É interessante verificar que as diversas facetas da Computação estão sendo apresentadas para as estudantes do ensino médio, mostrando a diversidade da área.

\section{Considerações Finais}

Por meio da análise dos trabalhos publicados no X Women in Information Technology (WIT), com base nas três questões de pesquisa, foi possível identificar alguns projetos brasileiros, suas instituições responsáveis e seus estados de origem. Tais projetos propõem uma visão mais ampliada da educação com o estabelecimento de alianças entre docentes, profissionais da área e estudantes em busca do mesmo objetivo: mais mulheres na Computação.

Os indícios encontrados nessa pesquisa, apontam que grande parte das ações promovidas pelos projetos são organizadas por docentes e estudantes universitárias(os), que trabalham de forma voluntária.

Entretanto, é importante ressaltar que a análise aqui realizada concentra-se em um único evento. Inúmeras outras ações e projetos são realizados no Brasil por diversos grupos independentes, empresas e outras instituições de ensino. É imprescindível intensificar a chamada de trabalhos das próximas edições do WIT para que projetos e ações realizadas em outros contextos, além dos acadêmicos da área de Computação, compartilhem suas experiências.

Para o Programa Meninas Digitais, dado que a maioria dos projetos relatados tem relação com esta ação da $\mathrm{SBC}$, este estudo contribui para o alcance das estratégias planejadas para consolidação do programa [Maciel; Bim, 2016], entre as quais está o

4 http://meninas.sbc.org.br/index.php/projetos/ - em 01/04/2017 constavam no site 28 projetos cadastrados. 
estímulo a pesquisa e publicação de artigos das ações realizadas. Ainda, a coleta e análise de dados sobre o programa e seus projetos é fundamental para sua consolidação.

Por fim, apesar da crescente discussão sobre a presença das mulheres na área de TI ainda há muito trabalho a ser feito para alcançar a equidade de gênero dentro deste espaço. Como trabalho futuro, sugere-se a análise dos trabalhos publicados no X WIT que relatam pesquisas, experiências e outras estratégias. Além disto, o mapeamento de todas as ações realizadas no Brasil é imprescindível para que se crie uma rede mais articulada e mais coesa, fortalecendo os esforços para termos mais mulheres na Computação.

\section{Referências}

Maciel, C., Bim, S. A. (2016) "Programa Meninas Digitais - ações para divulgar a Computação para meninas do ensino médio", In: Computer on the Beach 2016, Florianópolis, SC. pp.327-336, http:/www.computeronthebeach.com.br/arquivos2016/Anais completos - Computer on the Beach 2016.pdf. Março.

Oliveira, A. C.; Moro, M. M.; Prates, R.O. (2014) "O. Perfil feminino em computação: Análise inicial". In: Anais do XXXIV Congresso da Sociedade Brasileira da Computação - Workshop de Ensino de Computação (WEI2014). pp. 1465 - 1474. 